\title{
FLOW STREAMLINING FOR COOLING IMPROVEMENT IN VENTILATED BRAKE DISC USING CFD AS DESIGN TOOL
}

(Date received:2.3.10/Date approved:21.5.11)

\author{
Kannan M. Munisamy ${ }^{1}$, Norshah Hafeez Shuaib ${ }^{2}$, Mohd. Zamri Yusoff ${ }^{3}$ and Savithry K. Thangaraju ${ }^{4}$ \\ ${ }^{1,2,3,4}$ College of Engineering, Universiti Tenaga Nasional, Jalan IKRAM-UNITEN, 43009, Kajang, Selangor \\ E-mail: ${ }^{1}$ kannan@uniten.edu.my
}

\begin{abstract}
This paper presents experimental and Computational Fluids Dynamics (CFD) investigations of the flow and heat transfer in ventilated brake discs. The validation CFD model is done using the straight blade (baseline design) configuration with available experimental data. Development of an experiment rig with basic measuring devices and uncertainty calculation are discussed. Then, unidirectional racing blade configuration is then further focused on the improvement of the brake cooling using the similar numerical setting. Conventional and streamlined ventilated brake disc are simulated using commercial CFD software FLUENT ${ }^{T M}$ and the parameters such as mass flow and heat transfer characteristics are compared. The streamlined ventilated blade design shows a significant improvement in terms of the mass flow and heat transfer coefficient compared to the conventional unidirectional design. This improvement is only achieved with enhancing the aerodynamic characteristics of the internal passage blade and without any additional mass at the disc brake.
\end{abstract}

Keywords: Computational Fluid Dynamics (CFD), Flow measurement, Ventilated Brake Disc

\subsection{INTRODUCTION}

Braking technology has improved tremendously throughout the twentieth century. In the last decade the requirement on the brake disc cooling is increased due to significant increase in vehicle speed, weight, and acceleration. Currently, following claims of higher cooling efficiency, the ventilated disc brake is fast becoming the state of the art in automotive braking system. Several works has been done to investigate the various aspects of performance of conventional and ventilated brake discs.

The earliest interest was shown by Newcomb and Elsherbiny [1] on wet brakes on road to cool down the high temperature on the brake disc. An analytical solution for temperature rise during braking and some result from road testing of a heavy vehicle were presented. The application is recommended for heavy vehicles like buses and lorries. The authors also presented a general view about energy dissipation and energy saving possibilities during braking. Dow [2] and Moore [3] reported work on experimental rig development for the whole brake system rather than a single brake disc. They performed series of dynamometer braking experiment at British Railways to study the appearance of hot spots on wheels for a number of brake shoe materials. There were considerable experimental evidence to show that the thermo elastic interactive take place in both disc and ontread railroad brakes. Yevtushenko and Ivanyk [4] have reported an analytical model to find the surface friction temperature which was validated with literature experimental data for railway and aircraft applications.
Laskaj and Murphy [5], in collaboration with The Ford Tickford Racing (FTR), studied the design of the cooling air ducting for disc brake of Glenn Seton's V8 racing car. The special brake pads made of titanium and ceramic need to be around $550^{\circ} \mathrm{C}$ to operate effectively. However in the real case the temperature was measured up to $750^{\circ} \mathrm{C}$. They reported that, at high temperatures brake fading happens whereby the metal surface losses the strength and surface friction. The friction coefficient decreases with increasing temperature, leading to more force required to be applied from brake pads to brake disc. Thus, more energy is transferred to heat, compounding the problem. The aim of the study was to increase cooling of the brake disc, which can be done by increasing exit velocity of the ducting to the disc and increasing the surface area that the air blows. It is known that the two means will increase heat transfer rate. Harmand et. al. [6] studied the convective heat transfer properties for a rotor-stator system with rotor outer radius of $310 \mathrm{~mm}$. The flow structure between the rotor and the stator was analysed by Particle Imaging Velocimetry (PIV) technique. Johnson et. al. [7] reported an interesting experimental work on flow visualisation through ventilated brake disc using Particular Image Velocimetry (PIV). Inlet flow measurement shows significant misalignment due to the swirling entry of the flow. In the internal flow passage, large separation is found on the suction side surface. A study on the thermal gradient appearance on the surface of railway brake disc is done by Panier S., et. al. [8]. A full scale test bench with infrared camera measurement on the rubbing temperature during braking was built and classification of hot spots was observed. The author stated that hot spots 
classifications from the experiments are the actual phenomena in railway and aircraft disc brakes with reference to other previous publications.

Besides the studies on the flow and heat transfer properties of brake discs, extensive work is reported on the vibration and noise factor of the brake disc system [9-13].

The aim of this paper is to report the effect on cooling of blade with streamlining the conventional unidirectional racing disk brake passage flow. The improvement in the cooling will directly affects the car performance especially for racing cars in critical corners and achieving top speed. Only with aerodynamic manipulation this can be achieved without any additional of mass of extra gadget at the brake system. The brake disc test rig developed for the purpose for the CFD model validation for the standard straight blade baseline design. Having validated the CFD models against the experimental data, the effect of blade streamlining on the disc cooling is investigated numerically. The brief outcome of the work was presented in the February 2008 IEM Bulletin [16] by the author and well accepted by IEM members presented. The complexity of the flow inside the brake disc made the experimental analysis rather difficult and expensive. The CFD on other applications is also briefed in the February 2010 IEM bulletin by the author [17].

The outline of this paper is as follow. In the next section, the geometry of the brake discs under consideration is detailed out. Section 3 describes the development of the experimental rig. Section 4 explains the experimental procedure and the results, including the error analysis. Section 5 details out the CFD models and its results compared to the experimental results obtained in Section 4. Section 6 discusses the effect of streamlining of the blade on the flow and temperature profiles inside the ventilated disc.

\subsection{BRAKE DISC SPECIMEN}

The actual size of the brake disc used in a commercial passenger car is replicated in the current work. The prototype is made of aluminum due its lower cost of machining and stability in term of oxidisation during storage. For the experimental rig, the straight (conventional) 36 blade brake disc design is used. The height and thickness of the blade are $10 \mathrm{~mm}$ and $4 \mathrm{~mm}$ respectively. The top view with blade design and dimension are shown in Figure 1.

For the CFD simulation, two dimension of ventilated disc brake are considered. The 36 and 48 bladed disc are used in this paper. The 36 bladed is from passenger car design and 48 bladed from race car design. The race car design is streamlined than the passenger car design as shown in Figure 2. Figure 2 also shows the comparison between the straight and ventilated blades brake discs.
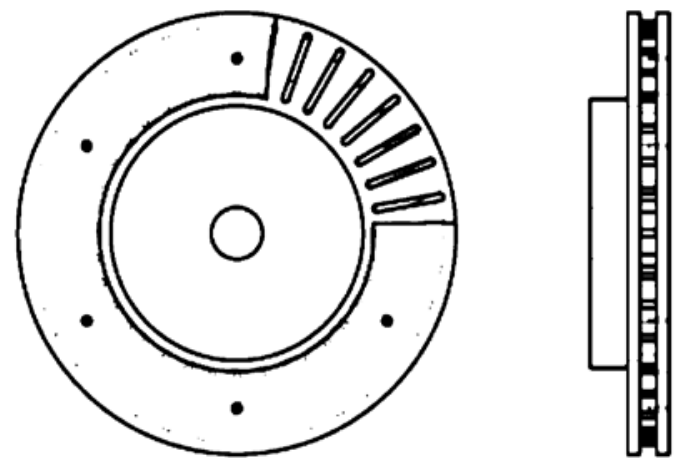

Figure 1: Top view of the straight blade ventilated brake disc

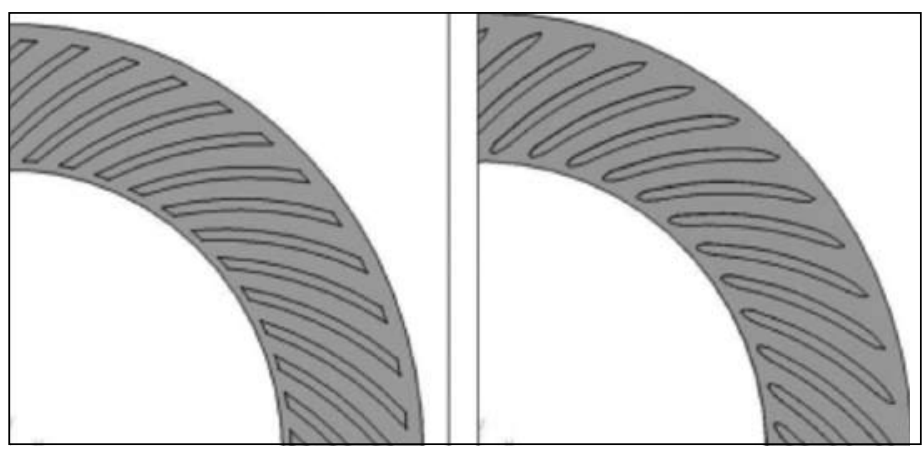

Figure 2: Two dimensional view comparison between a) the conventional and b) the streamlined disc brake design

\subsection{EXPERIMENTAL RIG DESCRIPTION}

The schematic of the experimental rig illustrated in Figure 3. As shown, to constraint the flow through the disc specimen, a specifically design brake disc casing is fabricated. In order to measure the air inflow velocity, an external flow circular ducting was built. Additional tapping is also made on the brake disc casing to tap the inlet and outlet pressure between the disc blades in radial direction. This experimental rig can be tested using various brake disc specimen with constant outer diameter. The maximum revolution is up to $2600 \mathrm{rpm}$ which is equivalent to $320 \mathrm{~km} / \mathrm{h}$ road speed.

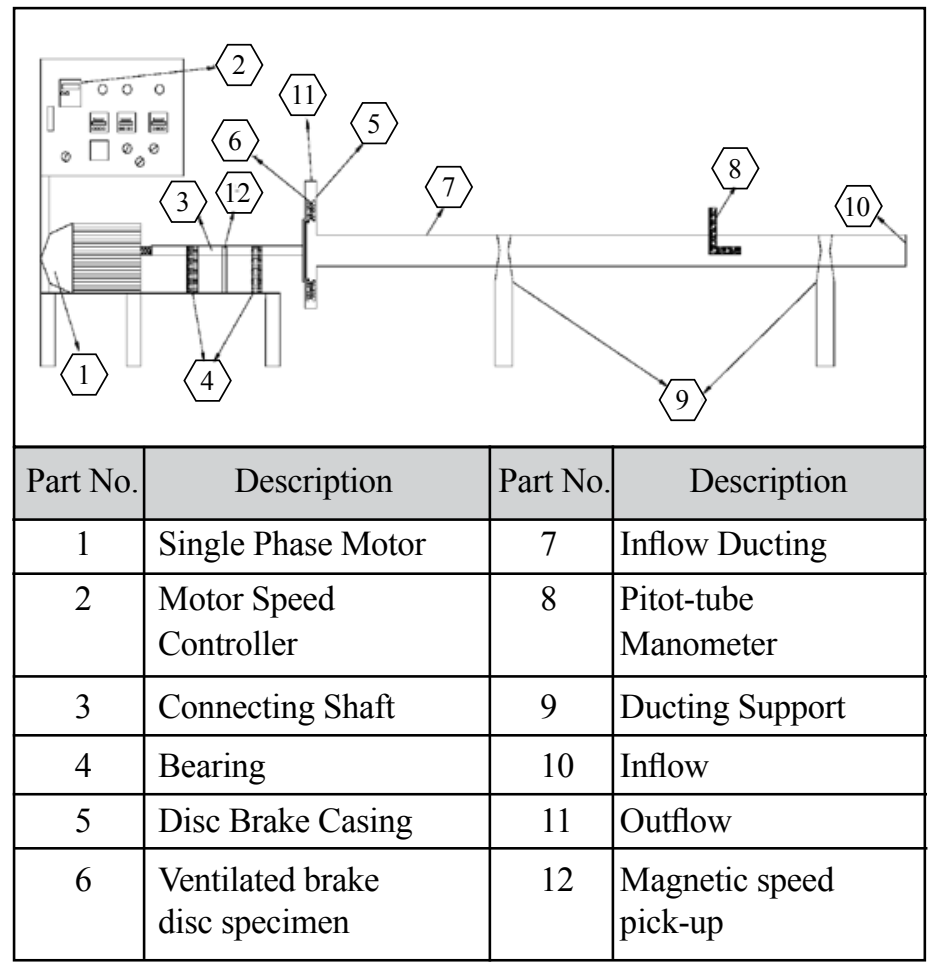

Figure 3: Schematic of experimental rig and the main components

\subsection{Flow Measurements}

The experimental rig is mainly developed to measure the amount air is metered into the ventilated brake disc and the pressure between the rotating blades. The inlet velocity is measured in the by taking the velocity integral in the inlet ducting. The screen which keeps the flow attached in a ducting is not needed because there is no sudden change in the diameter of the ducting [14]. Then, the entrance length, was calculated with reference to Munson et. al. (15) 


$$
\begin{aligned}
& \frac{1_{e}}{D}=0.06 R_{e} \\
& \frac{1_{e}}{D}=4.4 R_{e}^{\frac{1}{6}}
\end{aligned}
$$

The equation 1 is for laminar flow and equation 2 is for turbulent flow. The lowest Reynolds Number, corresponding to the lowest value of inlet velocity was found to be 9273 , which confirms that the flow is turbulent. Thus, equation 2 is used to calculate the entrance length. The entrance length $l_{e}$ is calculated to be $2.1 \mathrm{~m}$ for highest Reynolds number of 50,000 . Thus, a $2.5 \mathrm{~m}$ ducting is constructed for the pitot-static tube velocity measurement.

Figure 5 shows the pitot-static tube. The velocity of the free stream is calculated by the equation 3 below. The velocity in traverse direction (see Figure 6) is measured using pitot tube with reference to the BS1042. Then, the flow rate is calculated using multiple-application trapezoidal rule. An incline liquid manometer is used to measure the small static pressure difference.

$$
V=\sqrt{2 \frac{P_{3}-P_{4}}{\rho}}
$$

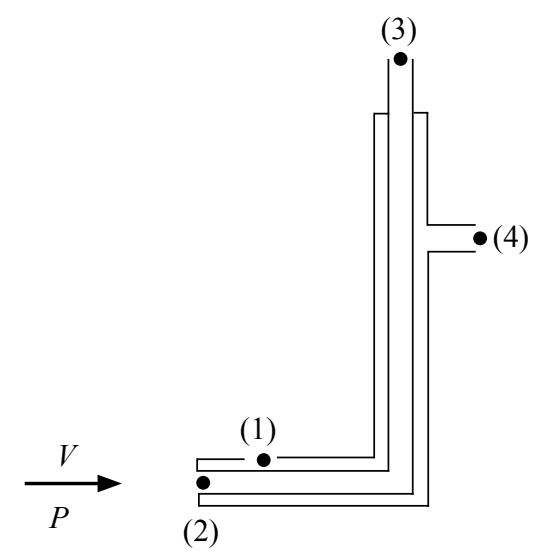

Figure 5: Pitot-Static tube

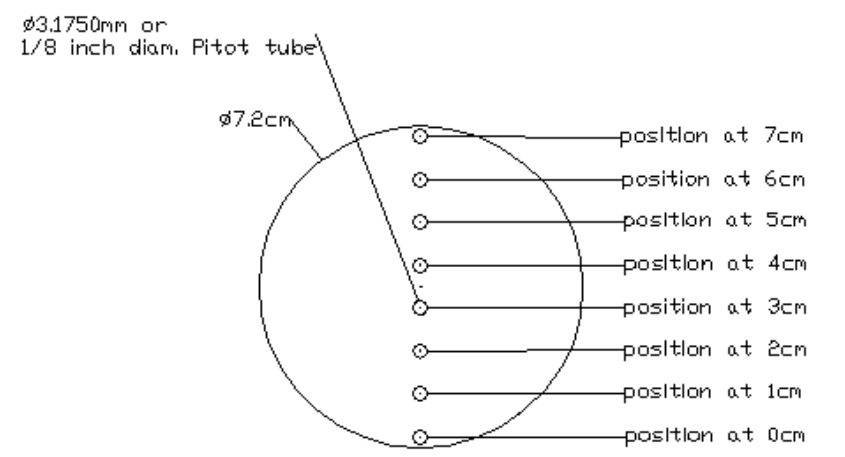

Figure 6: Traversed pitot tube positioning at 8 radial points in pipe cross-section

\subsection{EXPERIMENTAL RESULTS AND UNCERTAINTY ANALYSIS}

It is imperative that the flow measurements include the error analysis in order for it to be confidently compared with the CFD simulations. This forms the basis for the justification in using the CFD method for further analysis of streamlined brake discs.

Once the random and systematic errors in the experiment identified, they can be combined into an overall uncertainty of the measurement system. The usage of pitot-static tube to measure the velocity of incoming air flow need a detailed uncertainty analysis in order to reduce the error propagation in the experiment. The concept of repetition and random uncertainty are applied in the first stage of the measurement. The repetition method was used to reduce the random uncertainty associated with the fluctuation of readings. The already developed statistical concepts [16] were used to analyse the repeated readings and to estimate the effect of random errors.

In the current work, a pitot-static tube was mounted traversely (see Figure 6) at different radial positions in a given cross-section of the pipe to measure the air flow velocity. The stagnation and static pressure ports were connected to an inclined manometer with and $5^{\circ}$ inclination angles, having an accuracy of $\pm 0.25 \%$ in the readings. The pressure value from the manometer reading is used to obtain the velocity of the air flow equation 3 . An extensive calculation for the experimental errors is described in the Appendix.

Table 1 shows the summary of all the variables needed to obtain the volumetric flow rate, $Q$ and error, $\sigma_{Q}$ for discharge of air at straight blade disc rotating at $643 \mathrm{rpm}$. Table 2 shows the variation of total mass flow rate and error at different speeds for the straight blade brake disc.

Table 1: Volumetric flow rate and error for disc brake rotating at $643.06 \mathrm{rpm}$, straight blade disc

\begin{tabular}{|c|c|c|c|c|c|c|c|c|c|c|}
\hline $\begin{array}{c}\text { Radial } \\
\text { position }\end{array}$ & $\begin{array}{c}\boldsymbol{V}_{\text {avrg }} \\
(\mathbf{m} / \mathbf{s})\end{array}$ & $\begin{array}{c}\sigma_{v}^{+} \\
(\mathbf{m} / \mathbf{s})\end{array}$ & $\begin{array}{c}\sigma_{v}^{-} \\
(\mathbf{m} / \mathbf{s})\end{array}$ & $\begin{array}{c}\boldsymbol{V}_{\text {svmm }} \\
(\mathbf{m} / \mathbf{s})\end{array}$ & $\begin{array}{c}\sigma_{\text {svmm }} \mathbf{o r} \\
\mathbf{U v}(\mathbf{m} / \mathbf{s})\end{array}$ & $\begin{array}{c}\boldsymbol{A} \\
\left(\mathbf{m}^{2}\right)\end{array}$ & $\begin{array}{c}\sigma_{A} \\
\left(\mathbf{m}^{\mathbf{2}}\right)\end{array}$ & $\begin{array}{c}\boldsymbol{Q} \\
\left(\mathbf{m}^{\mathbf{3}} / \mathbf{s}\right)\end{array}$ & $\begin{array}{c}\sigma_{\boldsymbol{O}} \\
\left(\mathbf{m}^{3} / \mathbf{s}\right)\end{array}$ & $\begin{array}{c}\boldsymbol{Q}_{\text {error }} \\
(\mathbf{\%})\end{array}$ \\
\hline 0 & 2.1400 & 0.3618 & 0.4238 & 2.1091 & 0.3928 & 0.000311 & $5 \mathrm{E}-07$ & 0.000655 & 0.000122 & 18.6 \\
\hline 1 & 2.5724 & 0.3498 & 0.2959 & 2.5993 & 0.3229 & 0.000250 & $5 \mathrm{E}-07$ & 0.000650 & $8.07 \mathrm{E}-05$ & 12.4 \\
\hline 2 & 2.6177 & 0.2627 & 0.2279 & 2.6351 & 0.2453 & 0.000150 & $4 \mathrm{E}-07$ & 0.000395 & $3.68 \mathrm{E}-05$ & 9.32 \\
\hline 3 & 2.8844 & 0.2096 & 0.1934 & 2.8925 & 0.2015 & 0.000150 & $4 \mathrm{E}-07$ & 0.000434 & $3.03 \mathrm{E}-05$ & 6.98 \\
\hline 4 & 2.9596 & 0.2956 & 0.3020 & 2.9563 & 0.2988 & 0.000150 & $4 \mathrm{E}-07$ & 0.000443 & $4.48 \mathrm{E}-05$ & 10.1 \\
\hline 5 & 2.5742 & 0.2373 & 0.2632 & 2.5613 & 0.2503 & 0.000150 & $4 \mathrm{E}-07$ & 0.000384 & $3.76 \mathrm{E}-05$ & 9.79 \\
\hline 6 & 2.4855 & 0.2172 & 0.2619 & 2.4631 & 0.2396 & 0.000250 & $5 \mathrm{E}-07$ & 0.000616 & $5.99 \mathrm{E}-05$ & 9.72 \\
\hline 7 & 2.2947 & 0.2986 & 0.3585 & 2.2648 & 0.3285 & 0.000311 & $5 \mathrm{E}-07$ & 0.000703 & 0.000102 & 14.5 \\
\hline
\end{tabular}


Table 2: Total mass flow rate and error for disc brake at different speed for straight blade brake disc

\begin{tabular}{|c|c|c|c|}
\hline $\begin{array}{c}\text { Speed } \\
(\mathbf{r p m})\end{array}$ & $\begin{array}{c}\text { Total mass } \\
\text { flow rate, } \boldsymbol{m} \\
\mathbf{( k g / s )}\end{array}$ & $\begin{array}{c}\text { Error of } \boldsymbol{m}, \\
\left.\sigma_{\mathbf{m}} \mathbf{( k g} / \mathbf{s}\right)\end{array}$ & $\begin{array}{c}\text { Percentage } \\
\text { error of } \boldsymbol{m} \\
\mathbf{( \% )}\end{array}$ \\
\hline 643.06 & 0.015736 & 0.000772 & 4.91 \\
\hline 803.82 & 0.018476 & 0.000768 & 4.89 \\
\hline 964.58 & 0.021109 & 0.000904 & 4.28 \\
\hline 1125.35 & 0.024949 & 0.000740 & 2.97 \\
\hline 1286.11 & 0.028033 & 0.000621 & 2.22 \\
\hline 1446.88 & 0.030587 & 0.000630 & 2.06 \\
\hline 1607.64 & 0.034655 & 0.000684 & 1.97 \\
\hline 1800.00 & 0.040169 & 0.000698 & 1.74 \\
\hline 2000.00 & 0.042714 & 0.000703 & 1.65 \\
\hline
\end{tabular}

The measured inflow velocities for all rotational speeds are shown in Figure 7. As depicted, the curves in the Figure are not symmetric at the center line and the error bars intervals are noticeable, showing the effect of blockage bias.

In Figure 7, similar velocity profiles can be seen for the rotational speeds of $803 \mathrm{rpm}$ and $946 \mathrm{rpm}$. The velocity curve is rather smooth but still not symmetric at the center line for $1125 \mathrm{rpm}$, which shows the blockage bias for higher but moderate speed. However, the error bars for this curve is smaller compared to the curves for the lower speeds, indicating that the blockage bias exist because of the use of Pitot tube but the effect is less due to the higher flow velocity. The curves for speed $1607 \mathrm{rpm}, 1800 \mathrm{rpm}$ and $2000 \mathrm{rpm}$ are experiencing the same blockage bias, but the curve is not smooth. However, the error bars intervals are very small compared to previous curves.

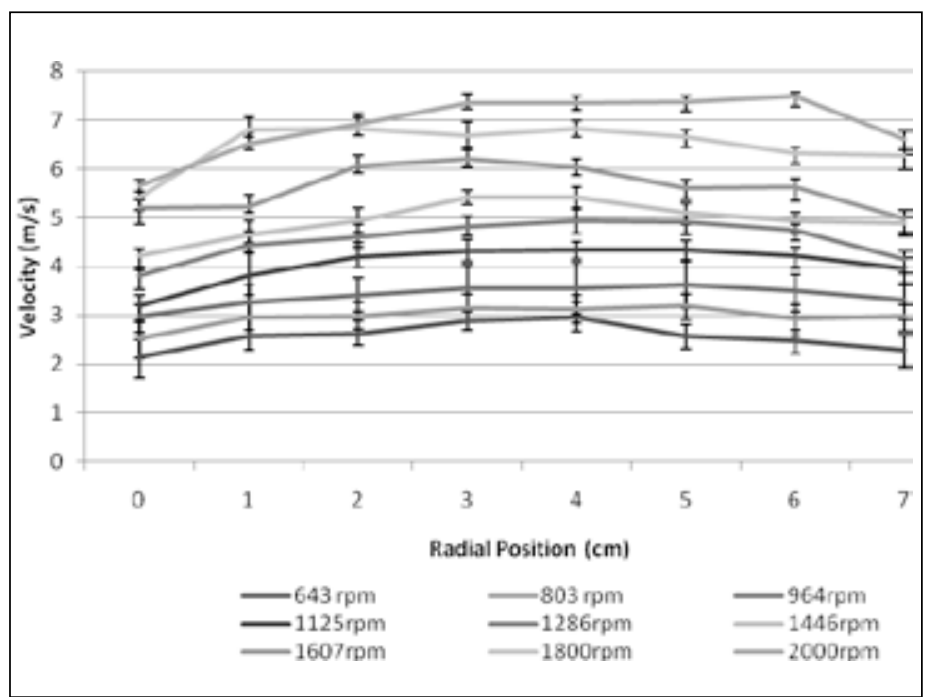

Figure 7: Traverse velocity result for different rotational speeds

Figure 8 shows the mass flow rate variation with increasing rotational speed. It should be noted that the error related to mass flow rate is comparatively low.

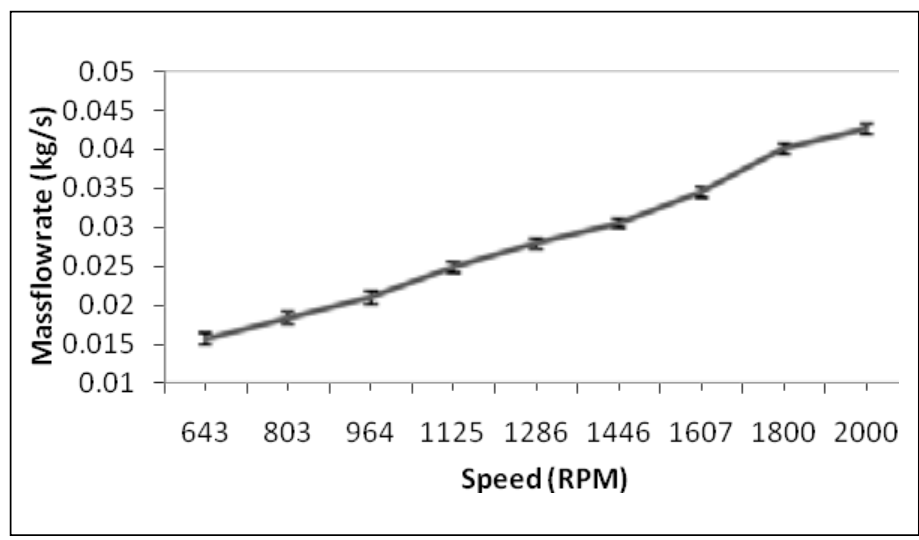

Figure 8: Mass flow rate for different rotational speeds

\subsection{CFD SIMULATION OF FLOW THROUGH STRAIGHT BLADE VENTILATED DISC AND COMPARISON WITH EXPERIMENTAL RESULTS}

The extensive measurement of flow velocity completed in the experimental analysis is then used as boundary conditions to CFD analysis. The commercial CFD software FLUENT ${ }^{\text {TM }}$ is used.

The flow is periodical in the circumferential direction, thus only $1 / 36$ th of the geometry is modeled. Figure 9 shows the computational model generated and the appropriate boundary conditions applied for the current problem. The model consists of 355000 mesh, comprising of tetrahedral and hexahedral elements. A grid dependency study was carried out and the optimal numbers of grid points which gave a satisfactory compromise between accuracy and computational time are chosen.

RNG k- $\varepsilon$ two-equation model is selected for the turbulence transport equations and standard wall treatment available in FLUENT $^{\mathrm{TM}}$ Segregated solver was chosen since the flow is relatively low speed and the pressure correction method is used for the flow field calculation. The computational model is then simulated for various rotational speeds with reference to the experimental configurations until the residual error is less than 105. The 3-dimensional computational results then post processed to extract pressure point data to compare with the blade inlet pressure experimental data.

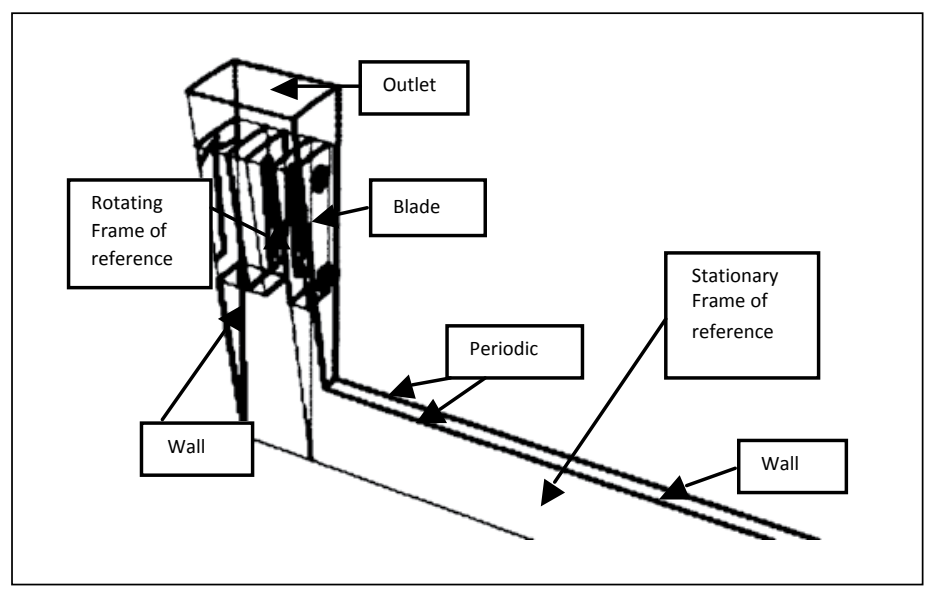

Figure 9: CFD Boundary conditions for straight blade ventilated brake disc 
Figure 10 shows the comparison between inlet pressure values obtained from CFD with the measured values from experiment. The trend shows that the inlet pressure reduces as the rotational speed increases. Some discrepancies can be seen in Figure 10; for the first two rotational speeds the differences are less than 5\% and the next 3 speeds the differences are around $7 \%$. The discrepancy at high rotational speeds could be due to the highly swirling flow and thicker dead flow zones developed in the real case as presented with the CFD results in Figure 11. Looking at Figure 11 the low rotational speed has smaller dead flow zones or blue color regions. As the speed increase like in the $1446 \mathrm{rpm}$ and $1800 \mathrm{rpm}$ the rear side of the blade has more obvious blue color region which contributes to high drag through the blade passage.

Figure 12 below illustrates the CFD results of velocity vector distribution at mid-plane view of the brake disc. The figures show a major recirculation at the pressure side in anti-clockwise direction and a minor recirculation at the trailing edge pressure side in clock-wise direction. The trend is the same for all rotational speeds, with recirculation velocity increasing with increasing rotational speed. The velocity is deflected towards clock-wise at the entrance of the ventilated blade due to the rotational velocity component added to the radial velocity. The

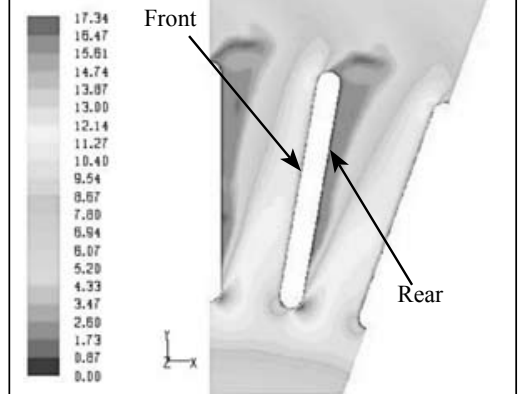

(a) $803 \mathrm{rpm}$

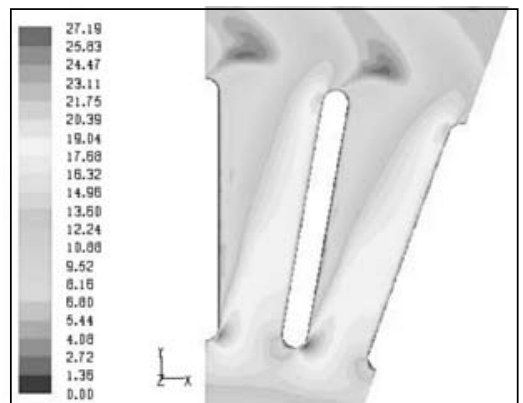

(c) $1286 \mathrm{rpm}$ ventilated blade mis-alignment for the rotational velocity range below is obvious with the recirculation presence. The increase in the velocity with rotational speed supports the trend of mass flow rate shown in Figure 8.

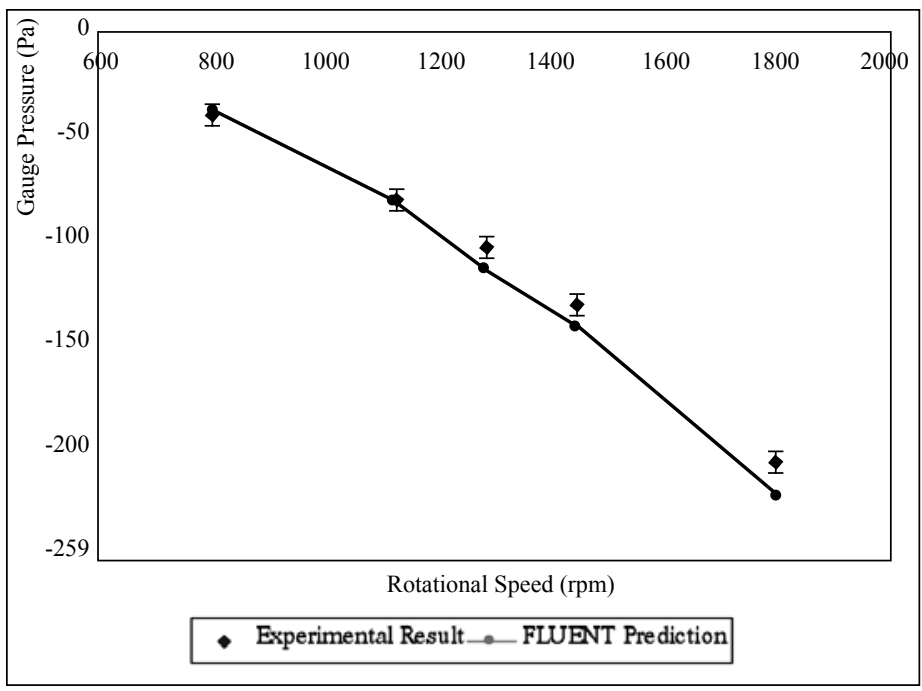

Figure 10: Comparison of simulation results against experimental for blade inlet pressure

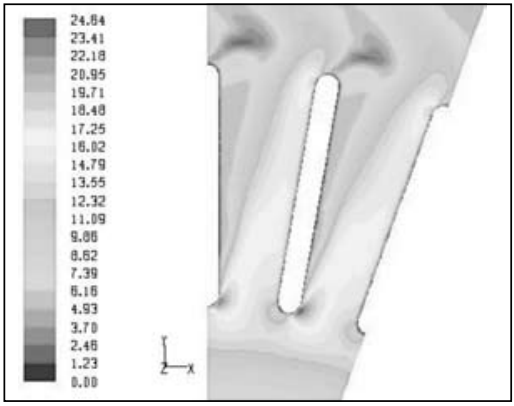

(b) $1125 \mathrm{rpm}$

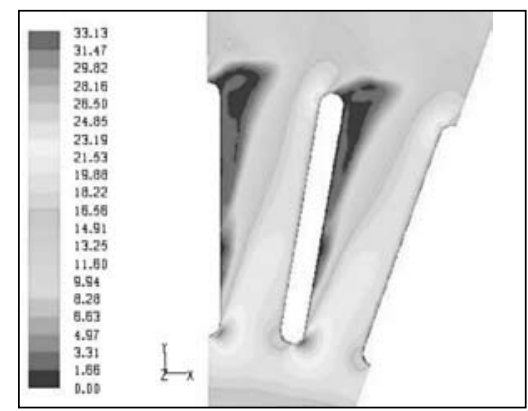

(d) $1446 \mathrm{rpm}$

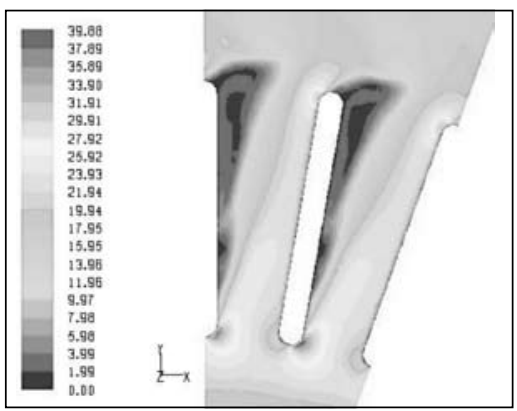

(e) $1800 \mathrm{rpm}$

Figure 11: Velocity contour plot for straight blade (baseline) brake disk designs 
The CFD result above predicts well the insight to the flow through ventilated blades. The boundary condition assumed and turbulent model used is validated with the close correlation with experimental data as in Figure 10.

\subsection{CFD SIMULATION OF FLOW AND HEAT TRANSFER THROUGH STREAMLINED UNIDIRECTIONAL VENTILATED DISC}

The race car ventilated disc brake configurations were further simulated in CFD for heat transfer calculation to investigate on the streamlining effect on the leading and trailing edge. The simulation configuration was done in three rotational speeds.

First the disc is simulated with a design rotational speed of $147 \mathrm{rad} / \mathrm{s}$, which is equivalent to $100 \mathrm{mph}$ road speed. Two off-design cases are simulated for both designs at $73 \mathrm{rad} / \mathrm{s}$ and $220 \mathrm{rad} / \mathrm{s}$ rotational speed, which are equivalent to $50 \mathrm{mph}$ and $150 \mathrm{mph}$ road speed respectively. The brake wall was set to be isothermal at $300^{\circ} \mathrm{C}$ to simulate the braking heat.

Figure 13 compares the calculated mass flow rates for both conventional and streamlined brake disc designs for all 48 blades. The mass flow ranging from $20 \mathrm{~g} / \mathrm{s}$ to $100 \mathrm{~g} / \mathrm{s}$. Both mass flow increasing linearly with rotational speed and streamlined

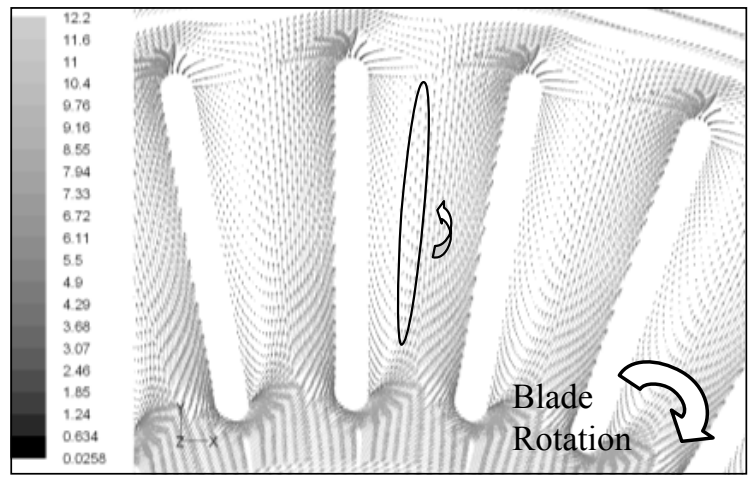

(a) $803 \mathrm{rpm}$ rotational speed

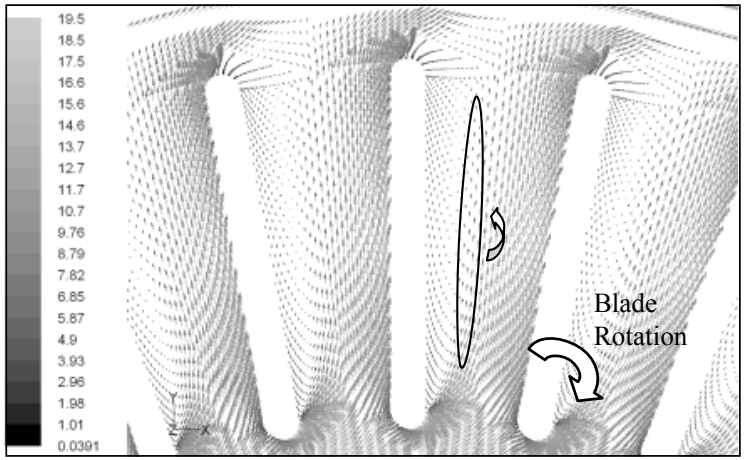

(c) $1286 \mathrm{rpm}$ rotational speed brake disc design is superior. In Figure 14, the blade wall heat flux is plotted for all three rotational speeds and for both brake disc designs. Both Figures show the improved heat transfer and mass flow rate between the two designs, which increase almost linearly with increasing rotational speed. This improvement has a close relationship with the velocity distribution in the flow passage of the brake disc and the velocity incidence angle, which is reduced for the streamlined design as compared to the conventional brake disc. The cooling characteristic of the brake disc shows a great improvement with the new streamlined ventilated brake disc. The mass flow rate improves by approximately $47 \%$ and wall heat flux improves by $28 \%$.

Figure 15 illustrates the velocity vectors for both conventional and streamlined blades. It is observed that the streamlined brake disc velocity vectors are more uniformly distributed with higher velocities compared to the conventional design. In comparison the inlet velocity differs slightly between conventional and streamlined brake disc design. The conventional brake disc design has a lower velocity at the inlet compared to the streamlined brake disc design. Moreover, a smoother increase in the velocity pattern stream-wise can be seen for the streamlined brake disc design as compared with the conventional one.

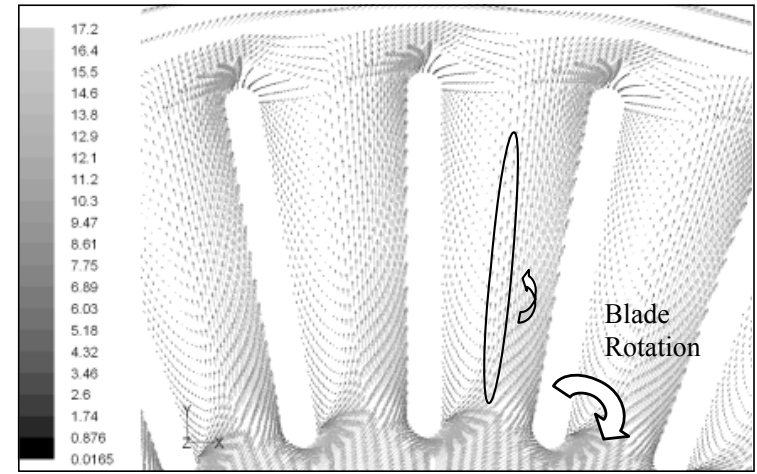

(b) $1125 \mathrm{rpm}$ rotational speed

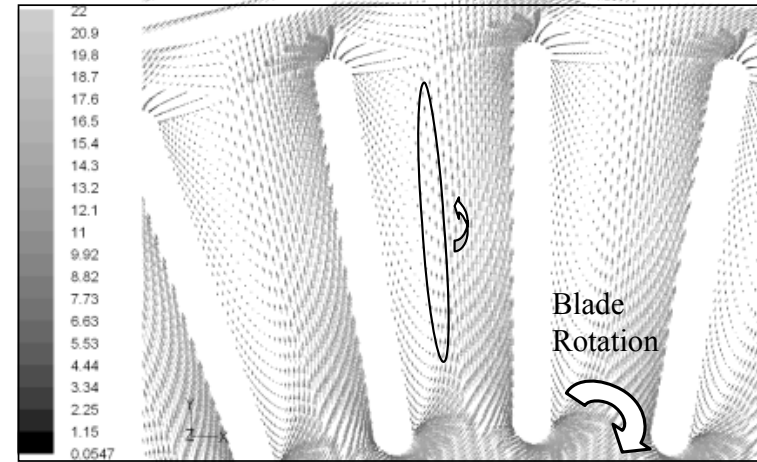

(d) $1446 \mathrm{rpm}$ rotational speed

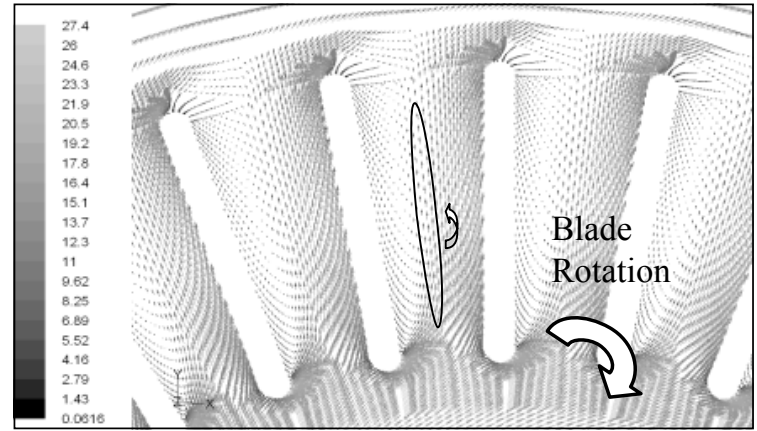

(e) $1800 \mathrm{rpm}$ rotational speed

Figure 12: Velocity vector visualisation plot for different rotationa speeds 


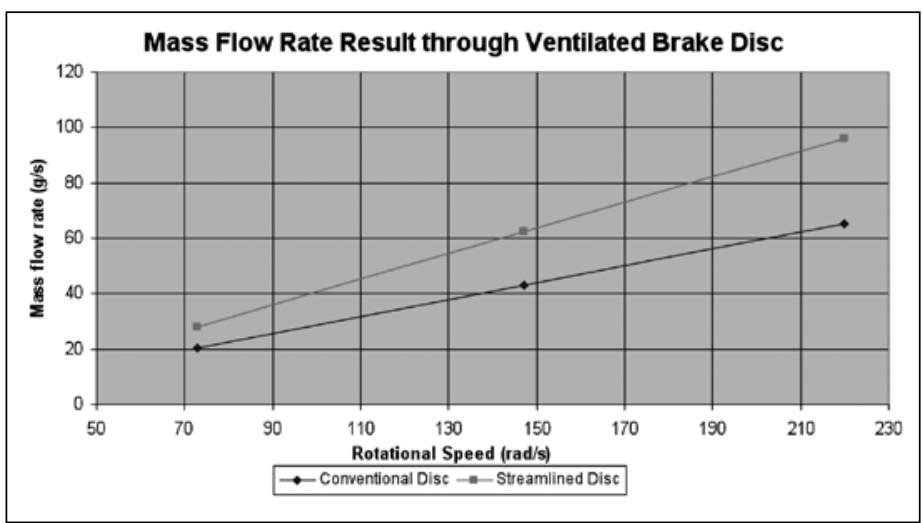

Figure 13: Mass flow rate comparison plot between the conventional and improved disc designs

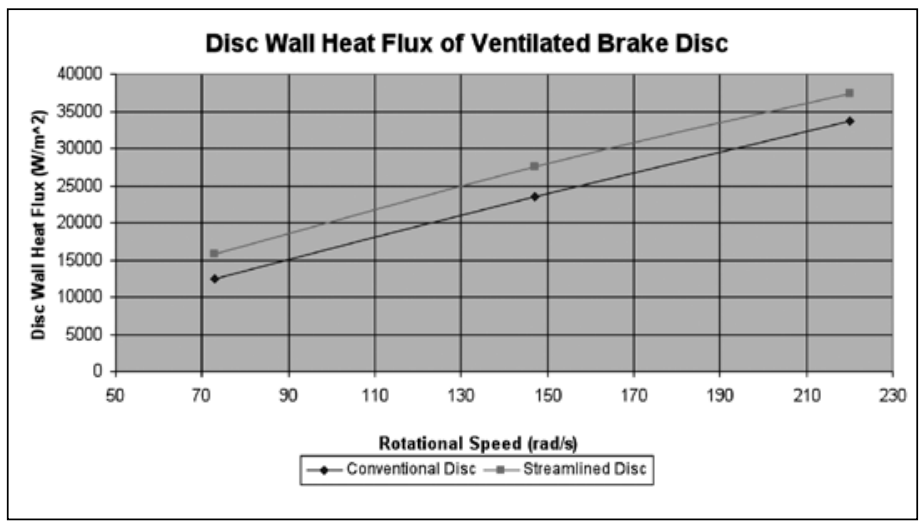

Figure 14: Heat transfer coefficient comparison plot between the conventional and improved disc designs

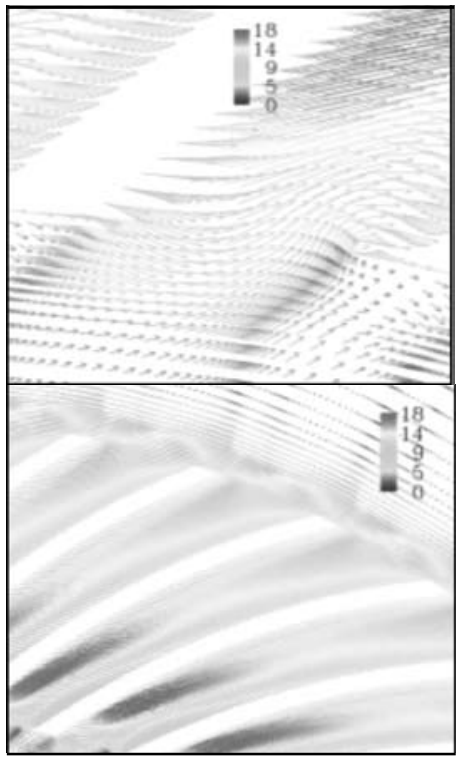

(a) Conventional disc at $50 \mathrm{mph}$

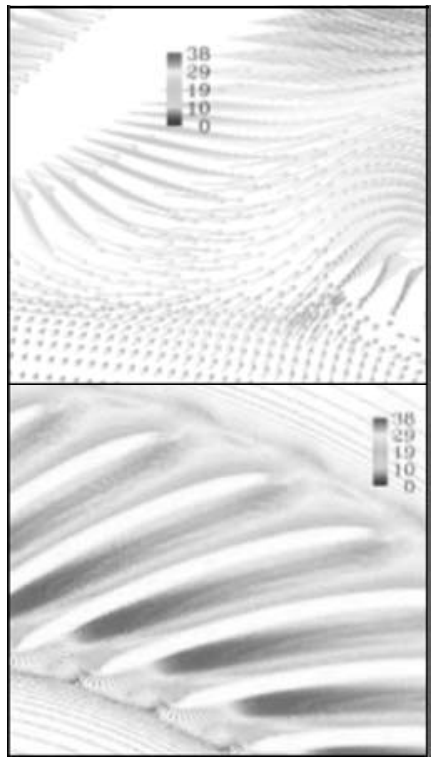

(d) Improved disc at $100 \mathrm{mph}$

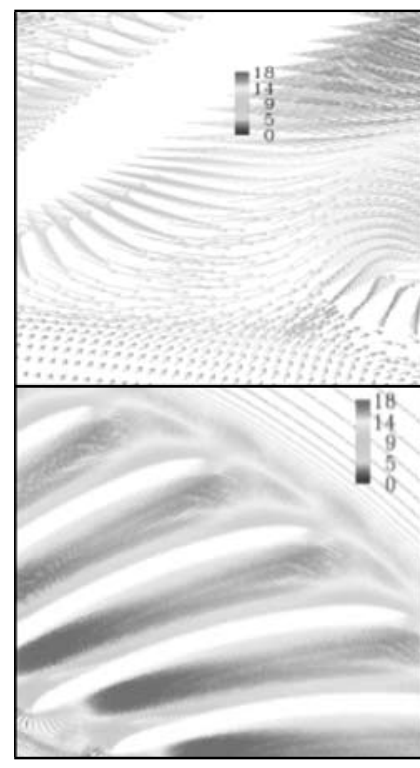

(b) Improved disc at $50 \mathrm{mph}$

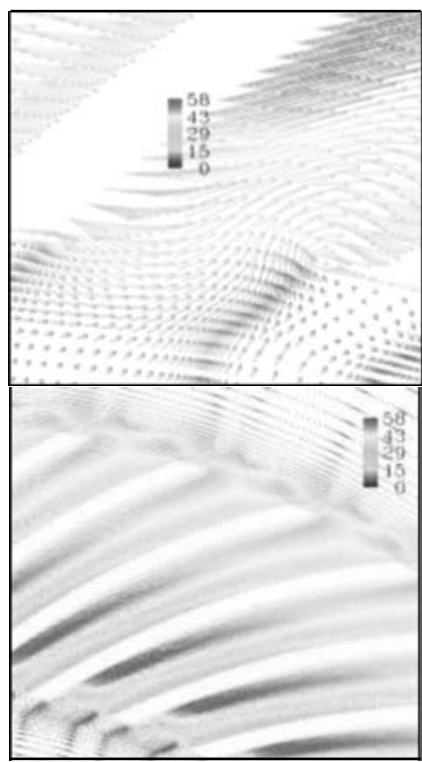

(e) Conventional disc at $150 \mathrm{mph}$

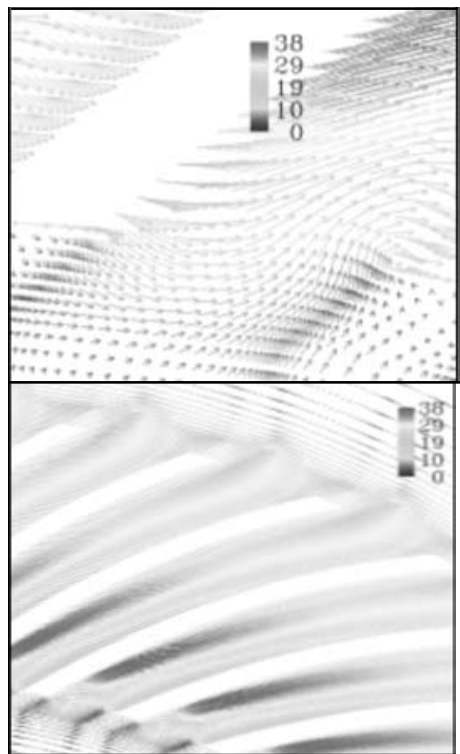

(c) Conventional disc at $100 \mathrm{mph}$

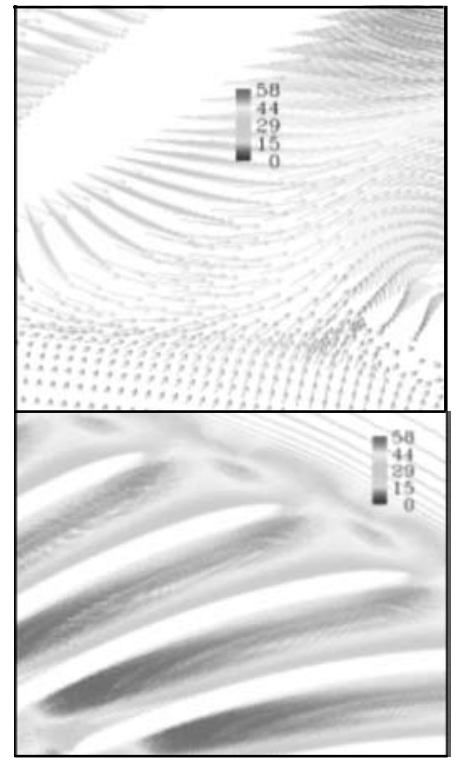

(f) Improved disc at $150 \mathrm{mph}$

Figure 15: 2-D Cut of the velocity vector $(\mathrm{m} / \mathrm{s})$ for all simulation configurations 


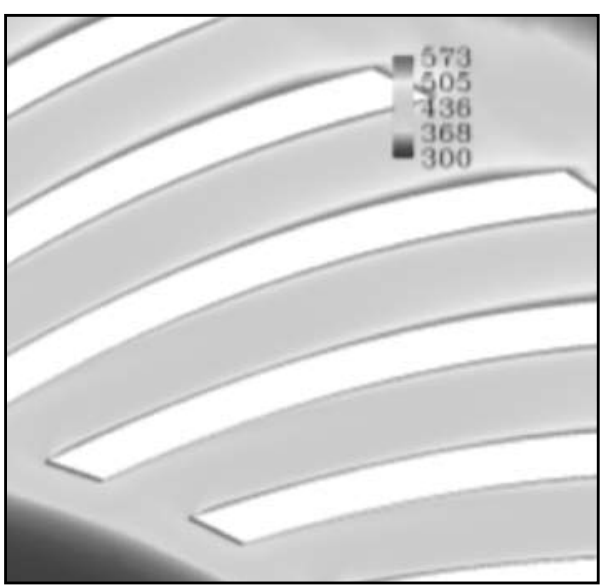

(a) Conventional disc at $50 \mathrm{mph}$

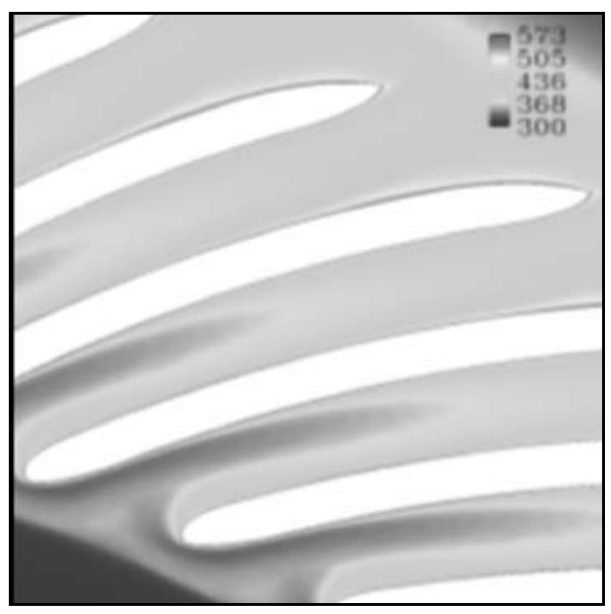

(d) Improved disc at $100 \mathrm{mph}$

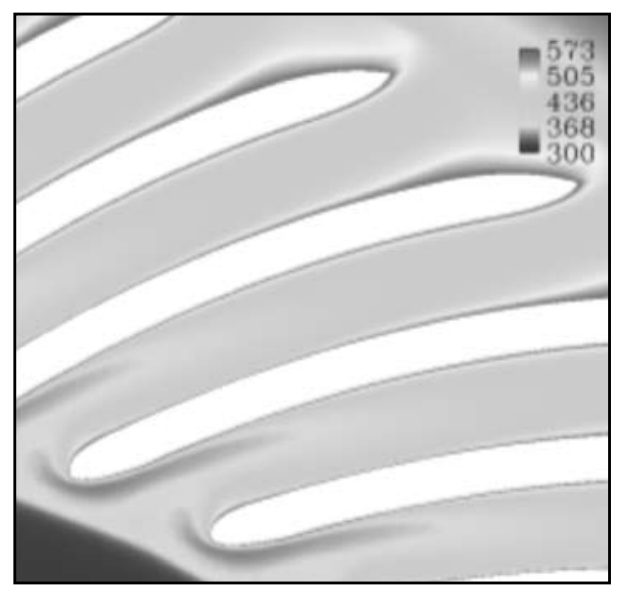

(b) Improved disc at $50 \mathrm{mph}$

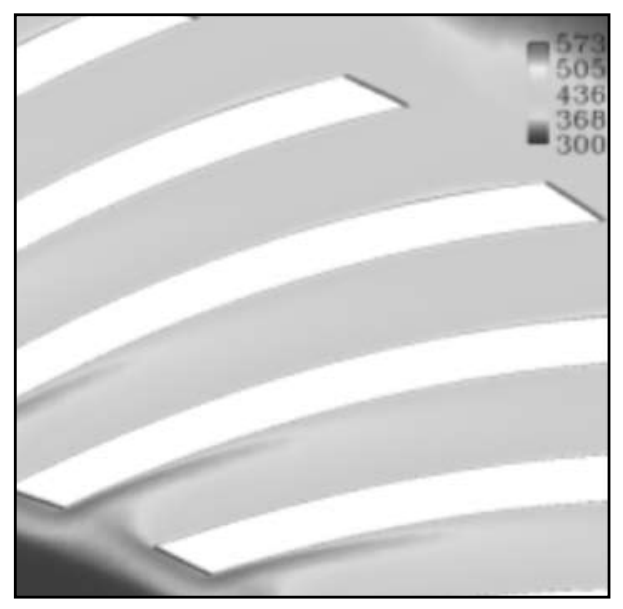

(e) Conventional disc at $150 \mathrm{mph}$

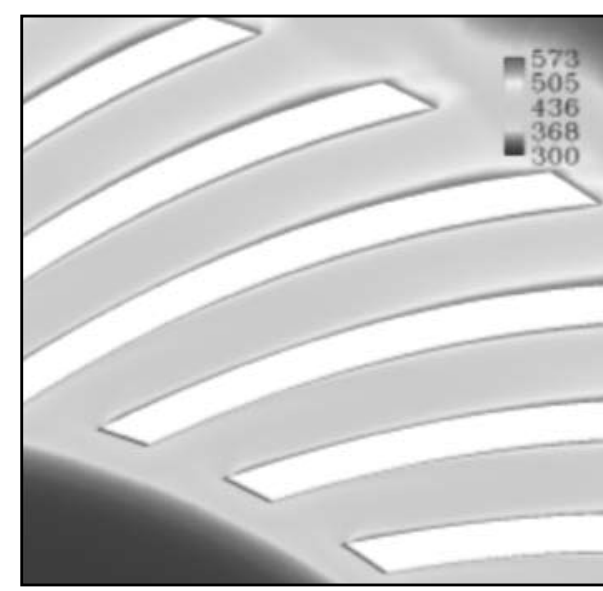

(c) Conventional disc at $100 \mathrm{mph}$

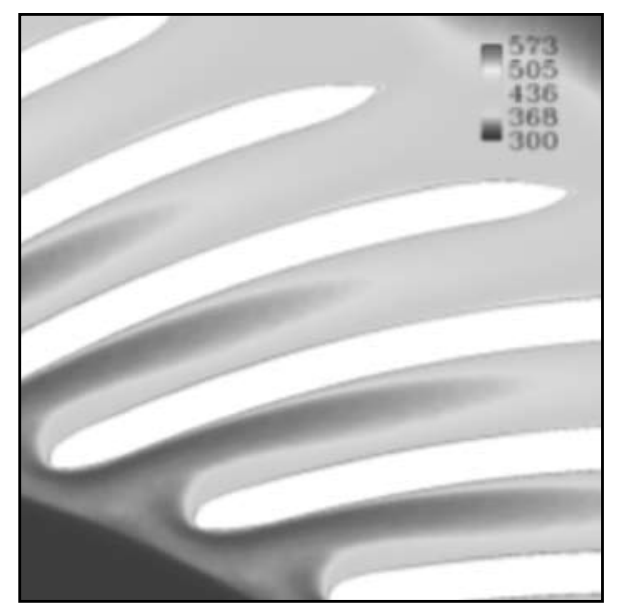

(f) Improved disc at $150 \mathrm{mph}$

Figure 16: Two dimensional cut of the temperature distribution (Kelvin) for all simulation configurations

The difference in velocity between the lower and upper surface of the improved brake disc is decreased, whereas the conventional design has a much higher velocity near the lower surface of the blade and a lower velocity near the upper surface of the blade. Streamlining the blade profile of the ventilated blades has the effect of smoothing the velocity profile.

Figure 16 shows the temperature distributions of the ventilated brake discs for both designs. The conventional design has a higher air temperature near the pressure side of the blade, whereas for the streamlined case, the temperature distribution is smoother from the inlet of the blade throughout the whole blade flow passage. This can be explained by the mass flow increment and uniformly distributed velocity profile for the streamlined brake disc. The increase in the mass flow is more effective in cooling, giving higher heat transfer coefficients.

\subsection{CONCLUSIONS}

The current work shows that a simple streamlining of the ventilated disc blade can have a significant effect on the cooling of brake disc. This is achieved with enhancing the aerodynamic characteristics of the ventilated blade. Thus, this will reduce the flow incidence angle of the rotational flow around the blade, resulting in an increase in the mass flow rate. This results in the improvements of the heat transfer coefficient. From CFD simulations, both the mass flow and the heat transfer rates increase linearly with the rotational speed. Simple streamlining of the blade is predicted to be worthwhile giving a substantial improvement in ventilated brake disc performance.

\subsection{ACKNOWLEDGEMENTS}

The author would like to acknowledge the Ministry of Science, Technology and Innovation of Malaysia (MOSTI) and Universiti Tenaga Nasional for the financial support for this project. 


\section{REFERENCES}

[1] T.P. and El-Sherbiny, M. 1975, Wear, Liquid-cooled disc brake. Newcomb, pp. 311-317.

[2] Thermoelastic effects in brakes. Dow, T. A. wear, 1980, Vol. 59.

[3] Moore, D. F. IPC Design of a prototype braking simulator. Business Press: TRIBOLOGY International, 1980.

[4] Yevtushenko, A. and Ivanyk, E. Determination of heat and thermal distortion in braking systems. Proceedings of Wear, 1995, Vol. 185, pp. 159-165.

[5] Laskaj, Matthew and Benjamin, Murphy. Improving the efficiency of cooling the front disc brake on V8 racing car. Melbourne, 1999.

[6] Harmand, S., Watel, B. and Desmet, B. S. Local convective heat exchanges from a rotor facing a stator. Int. journal thermal science, 1999, Vol. 39, pp. 404-413.

[7] Johnson, D. A., Sperandei, B. A. and Gilbert, R. Analysis of the flow through a vented automotive brake rotor. Journal of fluid engineering, 2003, Vol. 125, pp. 979-986.

[8] Panier, S., Dufreney, P. and Weichert, D. An experimental of hot spots in railway disc brakes. Proceedings of Wear, 2004, Vol. 257, pp. 687-695.

[9] Vernersson, T. Thermally induced roughness of tread-braked railway wheels Part 1: brake rig experiments. Proceedings of Wear, 1999, Vol. 236, pp. 96-105.

[10] Cunefare, K. A. and Graf, A. Experimental active control of automotive disc brake rotor sequeal using dither. J. Journal of sound and vibration, 2002, Vol. 250, pp. 579-590.
[11] Sherif, H. A. Investigation on effect of surface topography of pad/disc assembly on sequeal generation. Proceedings of Wear, 2004, Vol. 257, pp. 687-695.

[12] Desplanques, Yannick, et al. Analysis of tribological behaviour of pad-disc contact in railway braking Part 1: Laboratory test development, comprises between actual and simulated tribological triplets. Proceedings of Wear, 2006, Vol. 262, pp. 582-591.

[13] Uyyuru, R. K., Surappa, M.K. and Brusethaug, S. Bangalore, 2007, Tribological behaviour of Al-Si-SiCp composites/ autmobile brake pad system under dry sliding conditions. Tribology International, Vol. 40, pp. 365-373.

[14] Mehta, R. D. and Bradshaw, P. Technical notes, design rules for small low speed wind tunnels. The aeronautical journal of the royal aeronautical society, 1979, pp. 443-449.

[15] Munsun, B. R., Young, D. F. and Okishi, T. H. Fundamentals of fluid mechanics: John Wiley \& Sons Inc, 1998.

[16] Kannan M., Aerodynamics of car disc brake, JURUTERA, The monthly Bulletin of The Institution of Engineers, Malaysia, February 2008.

[17] Kannan M. Soong, P.S., Jet Fan and CFD, JURUTERA, The monthly Bulletin of The Institution of Engineers, Malaysia, February 2010.

\section{PROFILES}

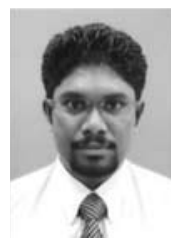

IR. KANNAN M. MUNISAMY graduated from UNITEN in 2000 with Bachelor of Mechanical Engineering (Hons). Then joined UNITEN as tutor. Upon completion of training with TNB as trainee engineer he pursued his Master Degree in Cranfield University, Milton Keynes, UK. He was conferred with Master of Science in (Aerodynamics) specialising in Computational Fluid Dynamics and currently serving as senior lecturer in UNITEN. With fundamental knowledge of CFD, various industrial consultancy projects were lead and contributed as team member. The consultancy projects including hydro power plant water flow problems, thermal power plant heat transfer related solutions, and air conditioning industry flow cases. Besides that, his expertise is in the area of automotive brake disk design and flow analysis for commercial and race car applications. He has lead couple of Ministry of Science and Innovation (MOSTI) funded projects on the development of brake disk experimental rig in lab located at UNITEN. He is also an active member of UNITEN CFD research group, IEM, IMechE, and SAE member. He has published in ASME Heat Transfer journal, international and local conferences. He is also reviewer for IMechE journals. $\mathrm{He}$ has vast experience operating CFD ACE+, GRIDGEN and FLUENT, commercial CFD software. Special interest is on rotating type of flow simulations. His industrial CFD and thermo-fluid engineering experiences are accredited by Board of Engineers Malaysia and Engineering Council, United Kingdom by granting him Professional and Charted Engineer status.

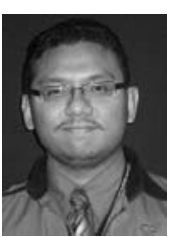

EN. NORSHAH HAFEEZ SHUAIB

College of Engineering, Universiti Tenaga Nasional, Jalan IKRAM-UNITEN, 43009, Kajang, Selangor

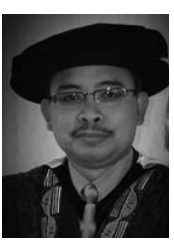

\section{IR. DR MOHD. ZAMRI BIN YUSOFF}

College of Engineering, Universiti Tenaga Nasional, Jalan IKRAM-UNITEN, 43009, Kajang, Selangor

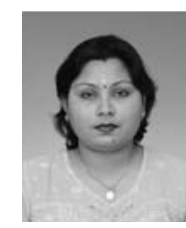

MS. SAVITHRY K. THANGARAJU

College of Engineering, Universiti Tenaga Nasional, Jalan IKRAM-UNITEN, 43009, Kajang, Selangor 